\title{
THE LENGTH OF THE LARGE AND THE SMALL INTESTINE IN YOUNG CHILDREN
}

\author{
LEWIS ROBBIN, M.D. \\ Assistant Resident Physician, Babies' Hospital \\ NEW YORK
}

The not uncommon evidence of an unusually long large intestine disclosed by roentgen-ray examinations of the intestinal tract has evoked very little interest until recent times. Scant reference is made in the literature of the past twenty-five years to the association of such conditions with serious intestinal disturbance. Works on anatomy, as a rule, give only a usual average length for the large and small intestine in adults. The only authority listed in the Index Medicus who gives any data on intestinal measurements is Curschman, who, in 1894, published observations on the relationship between the large intestine and body lengths in adults, and described a possible correlation between unusual measurements and the intestinal symptomatology of certain cases.

The observations reported in the present paper are based on measurements made at necropsy of the large intestine, small intestine and body length in 185 children, taken, for the most part, consecutively in the postmortem room of the Babies' Hospital. In the tabulation there have been compared the length of the large and the small intestine with the length of the body, and the length of the large intestine with the length of the small intestine. Record was made in each instance of the age, sex, condition of development and the anatomic diagnosis at necropsy. An investigation was also made to ascertain whether there was an association between any clinical symptoms present during life and the measurements found at necropsy.

The most striking, perhaps the only thing shown in Table 1 , is the enormous variation in the length of the large and the small intestine in each of the age periods.

The age periods are too few and the number of cases too small, especially after two years, to determine whether the body grows in length faster than does the intestine. The indications from the average measurements, however, are that it does grow faster than either the large or small intestine at this early period of life.

Tables 3 and 5 give the distribution of cases showing the relation of the body length to the length of the large and small intestine, irrespective of age. 
Table 1.-Average Length of Large and Small Intestine at Different Ages

\begin{tabular}{|c|c|c|c|c|c|}
\hline Age & $\begin{array}{c}\text { Number } \\
\text { of } \\
\text { Cases }\end{array}$ & $\begin{array}{l}\text { Average Length } \\
\text { Large Intestine, } \\
\mathrm{Cm} .\end{array}$ & $\begin{array}{c}\text { Range, } \\
\text { Cm. }\end{array}$ & $\begin{array}{l}\text { Average Length } \\
\text { Small Intestine, } \\
\text { Cm. }\end{array}$ & $\begin{array}{c}\text { Range } \\
\text { Cm. }\end{array}$ \\
\hline $\begin{array}{rl}0-1 & \mathrm{mo} . \\
1-6 & \mathrm{mos} \\
6-12 & \mathrm{mos} \\
12-24 & \mathrm{mos} \\
24-36 & \mathrm{mos}\end{array}$ & $\begin{array}{r}25 \\
84 \\
38 \\
26 \\
3 \\
5\end{array}$ & $\begin{array}{r}50.7 \\
\mathbf{5 9 . 3} \\
\mathbf{7 0 . 2} \\
\mathbf{7 5 . 0} \\
\mathbf{8 5 . 7} \\
106.0\end{array}$ & $\begin{array}{l}30-80 \\
35-83 \\
30-110 \\
55-105 \\
63-105 \\
90-120\end{array}$ & $\begin{array}{l}303.7 \\
384.4 \\
432.8 \\
453.5 \\
408.3 \\
468.0\end{array}$ & $\begin{array}{l}140-530 \\
172-520 \\
230-630 \\
320-645 \\
340-440 \\
390-560\end{array}$ \\
\hline
\end{tabular}

Table 2.-The Average Body Length at Different Ages and Ratio of Body Length to That of the Large and Small Intestine

\begin{tabular}{cccc} 
Average & $\begin{array}{c}\text { Avatio Average } \\
\text { Body Length, }\end{array}$ & $\begin{array}{c}\text { Ratio Average } \\
\text { Body Length to } \\
\text { Large Intestine }\end{array}$ & $\begin{array}{c}\text { Body Length to } \\
\text { Small Intestino }\end{array}$ \\
$0-1$ mo. & $\mathbf{C m .}$ & 1 to 1.09 & 1 to 6.6 \\
$1-6$ mos. & 46.2 & 1 to 1.05 & 1 to 6.8 \\
$6-12$ mos. & 56.5 & 1 to 0.88 & 1 to 6.0 \\
$12-24$ mos. & 72.5 & 1 to 0.99 & 1 to 6.0 \\
$24-36$ mos. & 75.5 & 1 to 1.05 & 1 to 5.0 \\
Over 36 mos. & 81.0 & 1 to 1.05 & 1 to 4.6 \\
\hline
\end{tabular}

TABLE 3.-Length of Large Intestine Compared with Body Length

\begin{tabular}{|c|c|c|}
\hline & Length & No. of Cases \\
\hline $\begin{array}{l}\text { From } 50 \text { to } \\
60 \text { to } \\
70 \text { to } \\
90 \text { to } \\
90 \text { to } \\
100 \text { to } \\
110 \text { to } \\
120 \text { to } \\
130 \text { to } \\
140 \text { to }\end{array}$ & 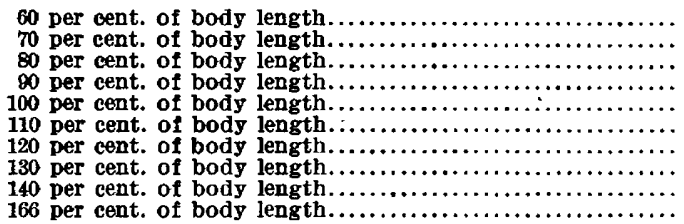 & $\begin{array}{r}1 \\
2 \\
7 \\
27 \\
37 \\
49 \\
36 \\
20 \\
4 \\
2\end{array}$ \\
\hline
\end{tabular}

TABle 4.-Findings Shown in Table 3 Summarized

\begin{tabular}{|c|c|}
\hline Length of I,arge Intestine & No. of Cases \\
\hline 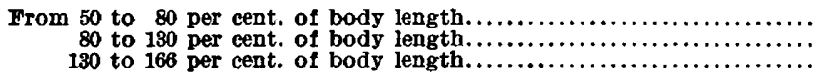 & $\begin{array}{r}10 \\
169 \\
6\end{array}$ \\
\hline
\end{tabular}

Downloaded From: http://archpedi.jamanetwork.com/ by a New York University User on 06/01/2015 
It will be observed that the length of the large intestine was between 80 and 130 per cent. of the length of the body in 91.3 per cent. of the cases; between 50 and 80 per cent. in 5.4 per cent. of the cases, and between 130 and 166 per cent. in 3.24 per cent. of the cases. The normal range of variation may be assumed to be between 80 and 130 per cent. of body length. The other groups would, then, contain what might perhaps be considered unusual or abnormal variations, comprising 8.6 per cent. of the total cases.

No clinical association could be established between the causative factors of illness or death and the measurements in the ten cases in which the large intestine was short. All children died of intercurrent acute infections; seven were males; three were females; the ages ranged between 5 days and $61 / 2$ months.

TABle 5.-Length of Small Intestine Compared with Body Length

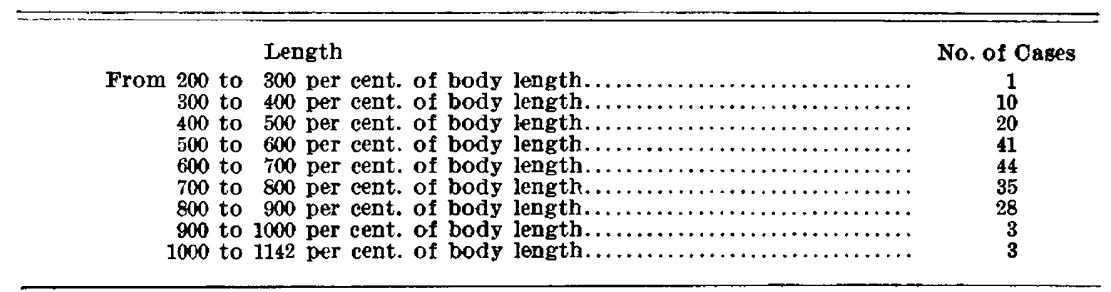

Table 6.-Findings Shown in Table 5 Summarized

\begin{tabular}{|c|c|c|}
\hline & Length of Small Intestine & No. of Cases \\
\hline From & $\begin{array}{l}200 \text { to } 500 \text { per cent. of body length } \ldots \ldots \ldots \ldots \ldots \ldots \ldots \ldots \ldots \ldots \ldots \ldots \\
500 \text { to } 900 \text { per cent. of body length } \ldots \ldots \ldots \ldots \ldots \ldots \ldots \ldots \ldots \ldots \ldots \\
900 \text { to } 1142 \text { per cent. of body length.... } \ldots \ldots \ldots \ldots \ldots \ldots \ldots \ldots \ldots\end{array}$ & $\begin{array}{r}31 \\
148 \\
6\end{array}$ \\
\hline
\end{tabular}

In the group of six cases of the abnormally long large intestine, five were males and one was a female; the ages ranged from $21 / 2$ weeks to 10 months. There was a history of chronic constipation in one case, although the infant was always carefully breast fed. Abdominal distention was noted in the physical examinations of three of the patients. A history of chronic intestinal disturbance was given in three cases diagnosed during life as marasmus.

In the measurements of the small intestine, it will be seen that the group in which the measurement was short contains 16.8 per cent. of cases measured; the median group contains 79.95 per cent., and the group of greatest length, 3.25 per cent. of the cases. We may, then, be justified in assuming that any measurement of the small intestine between 500 and 900 per cent. of body length may be considered within 
normal range. The other groups might, therefore, be regarded as containing the unusually short and unusually long small intestines.

No association could be discovered between the intestinal measurement and the clinical conditions in either the very short or the very long group. Of the eleven children with short measurements, five were males and six were females. Nine children were well formed and well nourished, and two were poorly nourished. In no case were intestinal lesions associated with nutritional disturbance of long standing.

In the group of six children with unusually long small intestines, four were males and two were females. None gave a history of chronic constipation or chronic distention. Two were premature infants.

An unusual length of one division of the intestinal tract was not necessarily accompanied by an unusual length in the other. In the six cases showing an unusually long large intestine in proportion to body length, the length of the small intestine was within normal range in every case; also in the ten cases showing an unusually short large intestine the measurement of the small intestine was within what we have considered the normal range.

Again, in the six cases in which the small intestine was unusually long the measurement of the large intestine was normal and where the small intestine was unusually short the large intestine relationship was normal.

It is quite evident from these observations that the length of the small and large intestine is subject to very wide variations. The large intestine may be only half the body length or more than one and one half its length. The small intestine may be only three times the length of the body, or it may be eleven times as long. It may be assumed that this difference in the length of the small intestine would not be accompanied by any clinical manifestations. But it is not improbable that an abnormally long large intestine might in later childhood or even in adult life be a condition of considerable importance, especially since the greater part of this increased length is in the sigmoid portion.

\section{SUMMARY}

1. The length of the large intestine was found to be between 80 and 130 per cent. of the length of the body in 91.3 per cent. of 185 bodies of infants examined.

2. The length of the small intestine was found to be between 500 and 900 per cent. of the length of the body in 79.9 per cent. of all cases.

3. An unusually long large intestine was not accompanied by an unusually long small intestine; an unusually short large intestine was not accompanied by an unusually short small intestine. 
4. No association of an unusually short or long small intestine with the clinical condition could be established.

5. No correlation could be established between an unusually short or long large intestine and the clinical condition. That the anomaly of an unusually long large intestine might be a potential factor in the causation of chronic intestinal indigestion or chronic constipation of later life is worthy of consideration.

6. The-indications are that during early life the body grows somewhat more rapidly in length than does either the small or large intestine.

The writer wishes to acknowledge the assistance of Dr. L. Emmett Holt in the preparation of this paper. 